\title{
THE MOSQUITOS OF SOME PORTS OF CHINA AND JAPAN.
}

\author{
By W. A. LAMBORs, \\ Malaria Bureau, Federated Malay States.
}

A mosquito survey, having as its object an enquiry into the distribution and prevalence in certain Far Eastern Ports of Stegomyia fasciata, the known carrier of yellow fever, was begun, on behalf of the Imperial Bureau of Entomology, by Dr. A. T. Stanton, whose report was published in the Bulletin of Entomological Research (Vol. x, pt. 3). As it seemed unlikely that he would be at leisure to complete the observations by a survey of the ports of China and Japan, as had been planned, the writer was instructed, in April 1921, by the Government of the Federated Malay States, at the suggestion of the Imperial Bureau, to complete the enquiry.

The following ports were accordingly visited with this object between April and June: Fuchow, Shanghai, Nagasaki, Kobe and Yokohama. The object of the present report is to afford an account of the investigation and of the observations made.

In a latitude so far north as that in which the enquiry was commenced, namely $26^{\circ} 8^{\prime} 4^{\prime \prime}$, it was hardly to be anticipated that a considerable variety of mosquitos would occur ; nor at the season, early spring, were great numbers of imagos to be expected. So difficult indeed was it to discover any at all, that it was found necessary to abandon the attempt to determine the presence of mosquitos by capture and to concentrate on the investigation of possible breeding places, a method the surer on account of recent experience, especially in the Malay States, of the breeding habits of the common Culicidae. By breeding, long series of adults were obtained, for it was found that the larvae of all species were little affected by the shaking they were subjected to in the course of travel, whether by land or sea. Thus the larvae obtained in Fuchow, China, afforded imagos fifteen days later in Nagasaki, in Japan ; imagos were obtained in Yokohama from larvae taken fourteen days previously in Nagasaki, 853 miles to the south by rail ; and imagos emerged on the steamer in Mid-Pacific, some 2,000 miles from land, from larvae taken eight davs previously at Yokohama.

\section{Fuchow.}

Fuchow, the capital of the Fukien Province of China, is situated in latitude $26^{\circ} 8^{\prime} 4^{\prime \prime}$ North and longitude $119^{\circ} 37^{\prime} 7^{\prime \prime}$ East on the north side of the Min river at about 35 miles from its mouth. It is $\mathbf{1 4 0}$ miles north of Amoy and 280 south of Hangchow.

The Foreign Settlement is on Nantai, a sniall island formed by the parting and rejoining of the river and connected with the town on the mainland by an old stone bridge. The Chinese town itself, with a population estimated at 600,000 , consists of a labyrinth of native buildings, largely one-storied, intersected in every direction by lanes, usially paved, and so narrow as to allow only foot traffic.

Except for a small hill partly occupied by the Foreign Settlement, which is hemmed in on all sides by the native quarters, the district is entirely flat and so little above water-level that with sudden rises of the river, which take place once or twice annually, the whole town becomes inundated. Rice-fields surround it on every side.

The river is crowded with craft of all descriptions, from large sea-going junks to smail two-oar and other boats trading with the interior. The town is not accessible to ocean-going vessels other than junks, larger ships anchoring about twelve miles down stream, at Pagoda Anchorage. 
Trade.-The trade of the port is mostly with other coastal places, for owing to trade depression, particularly in tea, for which until a few years ago Fuchow was one of the world's centres, large ships rarely put in. As showing how great has been the falling off in trade, it may be mentioned that, whereas in 1893 the total export of tea was $65,794,894 \mathrm{lb}$., it had dwindled to only $6,941,877 \mathrm{lb}$. by 1918 .

Steamers, mostly European-owned, run to and from Hong Kong, while the steamer trade to Shanghai is largely in the hands of the Chinese. During a part of the year motor schooners, trading under the Japanese flag, run to and from Formosa, and a very occasional ship brings kerosene from San Francisco.

Climate.-The seasons correspond roughly with our own, the summers being as a rule excessively hot, while in winter, when snow may fall, an icy blast sweeps down over the hundreds of miles of flat treeless country to the north. To data as to rainfall were available.

Water Supply.-There is no public supply. Water is usually taken from the Min at low tide and is slightly brackish, but there are a few surface wells in the graveyards, the only open spaces in the city. As is usual in native towns without a pipe supply, water is stored in large earthenware jars, which are also used for collecting rain-water.

Sanitation and Quarantine.-Such sanitation as is attempted appears to be due entirely to the demand for excreta for agricultural purposes. Scavengers, usually women, carrying uncovered wooden buckets, make a house-to-house collection day by day, and from time to time bale out the contents of earthenware jars disposed in odd corners for the convenience of passers-by, and vie with each other in seeking to obtain for sale such casual deposits as may be promiscuously made elsewhere. The material, after long storage in primitive septic tanks, is dumped on the ricefields. The effect of this pollution on mosquito breeding would seem to be a point well worth determining. Other waste water is either thrown directly into the street, or, escaping under the walls of the houses into a pit on the outside, forms possible breeding places. No measures against mosquitos are in force.

A European Medical Officer, under the Chinese Maritime Customs, is stationed at Pagoda Anchorage; all ocean-going ships are subject to his inspection and he is able to enforce quarantine there.

Such hospitals as there are in the town, with a total of about 250 beds, are connected with the various Missions, which in the past have attempted to deal with any epidemics that have arisen. During the outbreak of cholera in 1919 which, it is estimated, resulted in the death of no fewer than 40,000 people, a large number of temporary hospitals were erected by the American Red Cross.

Mosquitos.-The following is a list of the mosquitos obtained: Stegomyia albopicta, Skuse (= scutellaris, Theo.), Culex fatigans, Wied., C. tritaeniorhynchus, Giles, and A. hyrcanus, Pall. (= sinensis, Wied.).

Stegomyia albopicta.-The larvae of this species teemed in all water-jars left standing. These seemed to be the only breeding places available to the insect, which favours artificial breeding places; for the thrift of the Chinese leads them to collect all old tins, broken bottles and similar receptacles, such as in the vicinity of habitations in the Federated Malay States afford abundant opportunities for the insect.

It was usually possible to determine the species of larvae in particular vessels by examination of the adults found newly emerged on the inside at almost any hour of the day. But although long series of larvae were collected from numerous places, no single specimen of $S$. fasciata was obtained.

Culex fatigans.-The larvae of this species swarmed in the foul-smelling waste water from houses, and in certain ponds which had once been used for fish cultivation 
but have since served as dumping grounds for all sorts of organic refuse, chiefly of vegetable origin. They were also found sparingly in several places in ill-smelling water in pans placed under flower-pots. The species was certainly the dominant one in the town.

Culex tritaeniorhynchus. - The larvae of this species were found sparingly in the rice-fields associated with those of $A$. hyrcanus.

Anopheles hyrcanus.--The larvae of this insect were found in fair abundance on the outskirts of the town in the rice-fields, then at an early stage of cultivation, the planting out of the young plants from the nursery beds having only just commenced. It was noteworthy that in these beds, longer undisturbed than the open fields, the larvae were far more numerous than in the newly planted fields, possibly by reason of the presence of a larger amount of green filamentous algae, on the tufts of which they were invariably found. The larvae were either green in colour, or green with white splashes; or banding was present to a varying degree on the thorax, 3rd, 5th and 8th segments. They did not present that considerable diversity both of colour and pattern seen in those of the Malay States. Though ther rested on a green background, it was easy to see them when the sun's rays were oblique, but difficult to do so with the sun overhead.

\section{Shanghai.}

Shanghai, the great emporium of Central China and its most important free port, is situated in latitude $31^{\circ} 14^{\prime}$ North and longitude $121^{\circ} 29^{\prime}$ East on the left or west bank of the Huangpu River, about twelve miles above its junction with the Yangtze and at a distance of sixty miles from the North Saddle light at the river mouth.

Three distinct areas, each having its own municipal council, comprise the port, namely, the International Settlement, the French Settlement and the Chinese City. The area within the municipal limits is $8 \frac{2}{3}$ square miles, and the quinquennial census of the foreign and Chinese populations residing within the limits and of foreigners living on the outside roads, which was taken on 10 th October 1920 , showed a total of 26,869 foreigners and 1,661,098 Chinese. Among the foreign population the Japanese were dominant, numbering 10,215 ; the British coming next and numbering 5,341 . The figures do not include a vast Chinese population residing outside the Settlements.

The country round Shanghai, which is devoid of trees, is perfectly flat, stretching as a rich alluvial plain to the west over 45,000 square miles. The area round the town is little above sea-level, so that it does not present a great variety of possible breeding places for mosquitos.

Trade.-Shanghai is not only a port of trade, but is a large manufacturing and industrial centre to which ships come from all quarters of the globe.

Temperature and Rainfall.-The annual mean temperature is about $50 \cdot 9^{\circ} \mathrm{F}$. In July and August it runs up to a mean of about $81^{\circ}$, and in January and February drops to a mean of $36^{\circ}$ and $37^{\circ}$. In winter, snow and ice are occasionally seen, biting winds sweeping down from the north. A certain amount of rain falls throughout the year, the annual fall being about 39.97 inches, with a maximum fall of about five inches in June, July, December and February.

Water Supply.-The public supply for the International Settlement is drawn from the Huangpu, below the town; that for the French Settlement is obtained some distance above it. It is piped to most of the houses, or is obtainable from standpipes, so that there are practically no wells.

Sanitation and Quarantine.--The Health Department of the International Settlement, under British supervision, is a large one, consisting of a Director with three Assistant Health Officers, fourteen Sanitary Inspectors, and three Sanitary Overseers, 
with a large native staff. Anti-mosquito measures are thoroughly carried out. For the purposes of mosquito reduction a special staff of Chinese coolies is organised from the middle of March until the end of October, and works under the direction of Inspectors, who make written notes of those places where stagnant water occurs, such as Chinese gardens, empty houses and defective gullies, such spots subsequently receiving special attention.

By means of posters and leaflets in the languages commonly spoken an endeavour is made to instruct the people as to the necessity for mosquito control, but the difficulties of this are enhanced by the supineness of the Chinese authorities controlling the part of the town outside the Settlements. Within the actual limits of these the search for mosquitos was fruitless; outside it the larvae of some dominant species were obtained abundantly, and it was said that mosquitos in the European part of the town are a nuisance, as a rule, only in the late summer, gradually extending in from the Chinese quarters.

The shipping and quarantine are under the control of the Chinese Maritime Customs. A medical officer visits ships when necessary and when they come from infected ports. The quarantine station, where hospital accommodation and fumigation apparatus are provided, is some miles down stream.

Mosquitos.--The following is a list of the species obtained: Stegomyia albopicta, Culex fatigans, Culex tritaeniorhynchus, C. virgatipes, Edw., and Anopheles hyrcanus. Three of these species, with Armigeres ventralis, Walk., are recorded in the report of the Health Officer of Shanghai for 1920 as having been collected in the course of examinations made by the staff. The two new records concern $C$. tritaeniorhynchus and $C$. virgatipes.

Stegomyia albopicta.-A search for four days in various parts of the International and French Settlements entirely failed to bring to light any larvae of Stegomyia. On the fifth day access was obtained, through the kind intervention of $\mathrm{Mr}$. E. Kilner, Chief Sanitary Inspector, to a Chinese-owned greenhouse, standing by itself and not at that season artificially heated, where in the water under five out of eleven little fern-covered rockeries kept in pans the larvae of this species were for the first time obtained. They were subsequently found in one other similar situation, but a further search for them elsewhere was entirely fruitless. No other species of Stegomyia was obtained. The scarcity of this insect at that time may well have been due to inclemency of season, which was said to have been unusually cold throughout, the mean daily temperature during the stay of five days in Shanghai being $61^{\circ}$, a bitter northerly wind blowing.

Culex fatigans.-The larvae of this species were found in open drains from houses and in the trenches draining vegetable plots.

Culex virgatipes. - This species was found in the same breeding places with C. fatigans, but in greater abundance.

Culex tritaeniorhynchus.-A single female example of this species, of very large size, was bred from a pupa found in a small swamp associated with those of A. hyrcanus.

Anopheles hyrcanus.-The larvae of this species were obtained in fair abundance $\mathrm{n}$ foul and stagnant water in swamps on the outskirts.

\section{Nagasaki.}

Nagasaki is situated in latitude $32^{\circ} 45^{\prime}$ North and longitude $129^{\circ} 52^{\prime}$ East, at the head of an inlet some three miles long at the western extremity of the island of Kyushu, which is about 469 miles from Shanghai. Being the most southerly of the ports of Japan it is the first port of call of the eastward steamers from India, the South Seas, China and the Philippines. It is largely built at the foot of hills 
forming a basin, but the houses extend up into the valleys to an elevation of about $400 \mathrm{ft}$. It has a population estimated at 176,480, and, in point of size, ranks next after Kobe in Western Japan.

Trade.-It is noted as a coaling station, the coal being obtained chiefly from Takashima, an islet eight niiles south-east of the entrance to the harbour, and in lesser quantities from two adjacent islets.

There are no large industrial concerns in the south of Japan other than the shipbuilding yards at Nagasaki, and the exports are therefore small.

Temperature and Rainfall.-The climate is mild and equable, the mean annual temperature being from $60^{\circ}$ to $63^{\circ} \mathrm{F}$, with extremes of $40^{\circ}$ to $45^{\circ}$ in winter, and $75^{\circ}$ to $85^{\circ}$ in summer. Snow and frost are unknown.

Water Supply.-Mountain torrents supply the outlying parts of the town with water; the supply to the centre is pipe-borne from reservoirs in the hills near by.

Sanitation and Quarantine.--A quarantine station, with shore hospital accommodation and apparatus for the fumigation of ships, exists at a distance of a couple of miles to seaward of the harbour, and similar provision is made at all the other large ports of Japan.

Mosquitos.-A greater number of species than was met with in Fuchow and Shanghai was to be expected in Nagasaki, by reason of the more genial climate and the greater variety of breeding places afforded by the natural features of the country. The following species were obtained: Stegomyia albopicta, Aëdes (Finlaya) togoi, Theo., Aëdes (Finlaya) japonicus, Theo., Culex fatigans, C. hayashi, C. tritaeniorhynchus, Armigeres obturbans, Walk., Lutzia vorax, Edw., Anopheles hyrcanus, A. lindesayi, Giles, and Anopheles punctibasis, Edw.

Stegomyia albopicta.-The larvae of this species were fairly abundant in artificial breeding places, usually in shaded situations and in pure culture. They were obtained in rain-water collected in earthenware jars, in saucers beneath flowerpots, and in the cement or stone basins beneath the little fern-covered rockeries which are so commonly seen in Japanese gardens. An oblong granite trough, shaded by the eaves of a house in the main street, afforded a vast number of larvae, and similar troughs, set beneath a roof of thatch in the court-yards of temples and containing water for worshippers to rinse their mouths and wash their hands, preparatory to entering the sacred edifices, almost invariably afforded larvae. Their security in such situations is to be explained largely by the wariness exhibited, the larvae all dropping to the bottom on the slightest disturbance of the water, and by there being no means of draining the water from the bottom of the receptacles, which are never completely empty. A little bowl, scooped in the top of a granite pillar placed in front of a stone image of Buddha in a small roofed wavside shrine, afforded larvae, which were also found there in the water in sections of bamboos placed for the reception of votive offerings of flowers. No specimens of $S$. fasciata were obtained.

Aëdes (Finlaya) togoi.--The larvae of this species were first obtained in enormous numbers in the centre of the town, on the hillside in a large uncovered cement tank holding some hundreds of gallons and used for the storage of rain-water. They were invariably found in the water-containing troughs cut in the solid stones forming the pedestals of the monuments in cemeteries, and in the granite vases, often of very large size, placed for ornamental purposes in gardens. Cups hollowed in boulders placed near the doors of houses, and containing water used for ablution purposes, often contained these larvae when in the open, and they were commonly found in water-containing hollows in rocks in partly dried-up beds of streams running down from the mountains through the town. 
A ëdes (Finlaya) japonicus.--This, unfortunately, was not recognised as a distinct species, until Mr. F. W. Edwards had made the determinations. It was found less abundantly than Aeiles togoi, though breeding in similar places, and, it is believed, mixed with this species.

Culex fatigans.- The larvae of this species were found abundantly in foul drains and cesspits. Such was the cleanliness of the town, in spite of the absence of any water-borne sewage system, that these breeding places were not discovered at all within its precincts. Open drains were found only in the vicinity on the countryside, usually about cattle-sheds and rarely near houses. Pits, open to the sky, either dug in the ground or cut in the rock, were dotted about the fields, and served as septic tanks into which collections of excreta were dumped, the contents being finally withdrawn for the purposes of agriculture. In such pits, whether containing comparatively fresh or thoroughly decomposed material, the larvae invariably. occurred in enormous numbers, in the former case in pure culture.

Culex havashi.-The larvae of this species were found in great abundance associated with those of (Anopheles punctibasis) in a small natural pond, almost dried up and completely shaded at all hours by trees.

Culex tritaeniorhinchus.--The larvae of this species occurred, as elsewhere, in rice-fields.

Armigeres obturbans.-A few imagos of this mosquito were obtained in houses. Their breeding places were not discovered.

Lutzia vorax.--The larvae of this species invariably occurred in some abundance in cesspits, though only when the contents were so thoroughly decomposed that algal growth had become possible. In such pits the larvae of $C$. fatigans were far less abundant then elsewhere, the reason for which became apparent when about $a$ dozen larvae of the Lutzia were collected into a bottle. They attacked each other with such ferocity that within an hour only two or three survived, and they fed freely on the larvae of fatigans on which a long series were bred to maturity. The pupae of this Culex however seemed to enjoy entire immunity from attack, possibly because at the surface they are not so readily seized by such assailants.

Anopheles hyrcanus.-The larvae occurred in great abundance in the rice-fields when at an advanced stage of cultivation, associated, as in Fuchow, with those of C. tritaeniorhynchus. As in Fuchow, thoroughly decomposed manure in a liquid state is poured on the fields, when they are first flooded ready for planting out the rice, but in Nagasaki a great abundance and variety of waste vegetable matter, such as cut grass, potato haulms, turnip tops, etc., are also thrown in and allowed to decompose before cultivation is commenced, the larvae being seemingly unaffected by the richness of the water in organic matter. In Nagasaki, as elsewhere in Japan, the larvae were similar in colour and pattern to those in the Chinese ports referred to.

Anopheles lindesayi.-Nine larvae, only, of this species were obtained, in clear chilly water bubbling up from a spring in the hillside, a habitat similar to that in which, as Dr. Hacker has written, he found them in India.

Anopheles punctibasis.- The larvae of this species were obtained in some abundance in the same muddy pool with those of $C$. hayashi. The insect has recently been described by Mr. F. W. Edwards (Bull. Ent. Res. xii. pt. 3, p. 274, Nov. 1921).

\section{Kobo.}

Kobe, situated in latitude $34^{\circ} 41^{\prime}$ North and longitude $135^{\circ} 11^{\prime}$ Fast on the Inland Sea of Japan, has recently superseded Yokohama as the principal port, the tonnage of vessels arriving and clearing amounting in 1919 to $36,100,000$, for it is accessible to the largest steamers. The town is situated on a strip of land from a 
half to one mile wide, between hills at the back and the sea, and so has a very long sea frontage. The population in 1919 was 588,124 , and the town is distant only 20 miles from Osaka, also on the coast, with a population of $1,400,000$. There is ample communication between the towns by steamers, trains and electric trams.

Trade.--The main trade of the Empire centres in Kobe, steamers from all quarters of the globe berthing there, after having, as a rule, first visited either Nagasaki or Yokohama.

Temperature and Rainfall.-These are practically those of Yokohama.

Water supply. - A piped supply is everywhere laid on from reservoirs in the mountains at the hack of the town.

Mosquitos.-The following species were obtained: S. albopicta, A. (Finlaya) togoi, A. (Finlaya) japonicus, C. tritaeniorhynchus, C. fatigans and A. hyrcanus, the larvae occurring in places similar to those in which they were found in Nagasaki. A species regarded by Mr. F. W. Edwards as $C$. pipions, I., though the male genitalia are not quite identical with those of European specimens, was here obtained for the first time, breeding in similar places to C. fatigans, if not mixed with it.

There seemed also to be a marked reduction in $A$. japonicus, for one specimen only was obtained, though $A$. togo $i$ occurred in great abundance.

\section{Yokohama.}

Yokohama is situated in latitude $36^{\circ} 26^{\prime}$ North and longitude $139^{\circ} 38^{\prime}$ East on Tokyo Bay, 18 miles south-west of Tokyo. It stands on a plain shut in by hills on either side. It is the sixth largest city in the Empire, with a population of 400,000 Japanese and 10,000 foreigners, who mostly reside in one quarter of the city.

Trade.-Its natural excellence as a harbour has made it one of the two greatest ports in the country, its imports and exports being second only to those of Kobe. All the steamer lines from China, India and Europe converge at Yokohama, and it is the first port of call for Trans-Pacific liners from the United States and Canada. It is in direct communication with ports of the west coast of Mexico and Central America, the ships of one of the large passenger lines, coming by way of the Panama Canal, taking from 23 to 27 days in making the journey from Panama to Yokohama, putting in at San Francisco en route.

Temperature and Rainfall.-The seasons correspond to our own, the mean temperature in the spring (March to May) being $55^{\circ} \mathrm{F}$., in the summer (June to August) $73.9^{\circ}$, in the autumn (September to November) $60.6^{\circ}$, and in the winter (December to February) $39^{\circ}$. The cold in winter is often severely felt owing to northerly winds. The rainfall is about 70 inches annually. There is a heavy rainfall during the winter and early spring months, and after an intermission of a couple of months, mild rains fall with some constancy in June. The latter rains, coming at a season when with rising temperature mosquito activity begins to be felt, serve to keep possible breeding places constantly full of water, a factor of importance as favouring at that season the increase of mosquitos. At Kobe, and in the south, these rains are less constant.

Water Supply.-A piped supply serves the whole city, but the collection of rainwater in unscreened vats and barrels is general, there being a demand for it for the dyeing of cloth.

Mosquitos.--The following were obtained: Stegomyia a!bopicta, Aëdes (Fınlaya) togoi, Culex pipiens, C. orientalis, Edw., and Anopheles hrranus.

Stegomvia albopicta. - The breeding places of this species were of the same type as in Nagasaki, though the larvae were obtained less freely than in the south. They 
were found, for example, in a hollow tree in one of the main streets, but were especially abundant in the cemetery of the Foreign Settlement, where plentiful breeding places were provided for them in the jam-jars, pickle-bottles, and similar inexpensive receptacles that had once contained those floral tributes, which, in accordance with pious custom, are at lengthening intervals placed upon the graves--until the decay of interest in the departed gives the female mosquito the reversion. The specimens here obtained were so diminutive as to make their recognition, which is usually so easy by reason of the very characteristic markings, difficult without the aid of a lens. Specimens taken in Fuchow and Shanghai were rather larger, but did not come up to the size of those ordinarily taken in the Malay States. The gradual diminution in size may well be due to conditions becoming more unfavourable to the species further north, for it was found repeatedly in the Malay States that poorness of the food supply resulted in the production of dwarfed imagos. The ability to attain maturity at all under such conditions is doubtless one of the reasons why this species and $S$. fasciata are so widely spread. All attempts to obtain in the Malay States dwarfed Anophelines by semi-starvation or by rearing them in unsuitable media failed : the larvae either attained a maximum growth and in due course aftorded imagos, or else perished after a prolonged period of larval existence.

Aëdes (Finlava) togoi.--This species was found in the various types of breeding places already alluded to. It was especially abundant in certain quarters in butts of rain-water, and large numbers were obtained in the yards of stonemasons, in the cavities of various granite receptacles, such as mortars, bowls and troughs of all sorts, shapes and sizes, ornamental vases, etc. At a particular temple, at the main doorway, the pillars on either side rested in huge iron tubs, holding gallons of water. Examination for larvae in one of these, in which there were three golden carp, was negative ; in the other, in which there were no fish, larvae swarmed. It had already been remarked that in none of the little ornamental ponds, invariably found in gardens of any size, were larvae found when goldfish were present. It was quite usual to find a few of these fish in surface wells and barrels of water, in which, again, no larvae were ever obtainable. While these larvae were invariably found in open situations, their near relation, $S$. albopicta, was found breeding, with very few exceptions, in thoroughly sheltered spots. The larvae of Aeddes japonicus were not obtained here at all.

Culex orientalis.--The larvae of this species were found associated with those of Anopheles hyrcanus, having seemingly replaced those of $C$. tritaeniorhynchus, which were abundant in the south.

Culex pipiens.-.-This again had entirely replaced C. fatigans, and was found breeding in great abundance in similar drains and ditches. fields.

Anopheles hyrcanus. - This was found in abundance, breeding, as usual, in rice-

\section{Conclusions.}

Confirmation of the opinion expressed by Dr. Stanton in his report that "a survey of the ports of China and Japan would show that the conditions are unfavourable for the propagation of Stegomyia fasciata, even in the warmer months "was, therefore, obtained in regard to the places visited. In view of a record (Theobald, Monograph of the Culicidae, i, 1901, p. 293) of the capture of a single specimen of the insect in Tokyo (C. H. B. Wood, 3.viii.1899), a three-days' search for it was made in the suburbs there, especially on the seaward side. None were obtained, so that one may well conclude that, whatever the history of this particular specimen, the species has failed to establish itself there. There are recent records, however, of its presence in Kowloon, in latitude $22^{\circ} 12^{\prime}$ North on the mainland opposite Hong Kong, though sparingly in the latter place (Stegomyia Survey in Hong Kong, Bull. Ent. Res., vi, 1915, p. 67), and in Formosa (Secrete, 1917, "Notes of Mosquitos of Formosa." 
Abstract in China Med. Journal, Shanghai) in latitude $23^{\circ} 5^{\prime}$ North, and so occasional specimens may find their way north, though as a factor in the spread of yellow fever, they would appear to be negligible.

The possibility of the establishment of yellow fever in the ports visited would seem to hinge on the potentiality of Stegomyia albopicta, and possibly other very near relatives, such as $A \ddot{e} d e s$ togoi and $A$. japonicus, to act as carriers of the disease. Mr. Kilner stated that in Shanghai these mosquitos are not seen during the colder months of the year, and this probably holds good of Fuchow, where bitter cold is also experienced. In Japan, which feels the benefit of the North Equatorial Ocean current, the seasons, especially in Nagasaki, are milder, and it would seem probable that here, with a mid-winter temperature no lower than $43^{\circ} 5^{\prime}$, imagos may be active all the year round.

The work was greatly facilitated in Fuchow by the kind and ready help of Dr. Cheah and of Mr. H. S. Brand, the Secretary of the local Chamber of Commerce. I must acknowledge, further, the assistance received in Shanghai from Dr. C. N. Davis, the Acting Director of the Department of Public Health, and from Mr. E. Kilner, Chief Sanitary Inspector, and express my indebtedness to Mr. F. W. Edwards for the determinations of the mosquitos obtained. 